\title{
Are All Granulomatous Lesions Tubercular?
}

\author{
Nikhil Gupta
}

Published online: 19 February 2015

(C) Association of Surgeons of India 2015

\section{Dear Editor}

We read the article "Focal liver tuberculosis: a case report" with great interest [1]. It was really an interesting case, and authors have discussed it very well. My only concern is that are we justified in labeling this lesion as tubercular despite absence of caseation and acid fast bacilli. There can be many other differential diagnoses of granulomatous liver lesions [2]. Hepatic granuloma is a unique inflammatory response that may be idiopathic or may be a response to a bacterial, viral, fungal, or parasitic infection. It may be a manifestation of drug-induced liver injury [2]. There are certain distinctive features which can identify tuberculous granulomas in the liver; these include acid-fast bacilli within the lesion, caseating necrosis with destruction of the reticulin framework (seen in up to $83 \%$ of lesions), irregular contours with a particularly dense cuff of lymphocytes surrounding the lesion, and few lesions, with a tendency to coalesce [3]. Apart from histopathology, we can identify this lesion by detection of mycobacterial DNA on tissue specimen using PCR ( $88 \%$ sensitivity and $100 \%$ specificity).
We should use all available diagnostic modalities to identify the lesion correctly as we know that all first-line antitubercular drugs are hepatotoxic, and prescription of these drugs to a patient having non-tubercular hepatic lesion may further worsen the clinical picture.

Conflict of Interest There are no conflicts of interest or financial ties to disclose.

\section{References}

1. Pandey A, Singh RK (2014) Focal liver tuberculosis: a case report. Indian J Surg 76(3):223-227

2. Turhan N, Kurt M, Ozderin YO, Kurt OK (2011) Hepatic granulomas: a clinicopathologic analysis of 86 cases. Pathol Res Pract 207(6):359365

3. Harrington PT, Gutiérrez JJ, Ramirez-Ronda CH, Quiñones-Soto R, Bermúdez RH, Chaffey J (1982) Granulomatous hepatitis. Rev Infect Dis 4:638-655
N. Gupta $(\bowtie)$

Department of Surgery, PGIMER and Dr RML Hospital, Delhi, India

e-mail: nikhil_ms26@yahoo.co.in 